\title{
Libertad de expresión y pluralismo informativo: compatibilidades y tensiones en el contexto de la televisión
}

\section{Freedom of speech and media pluralism: compatibilities and tensions in the context of broadcasting television}

RESUMEN

La manera como se resguarda el pluralismo informativo en los medios de comunicación depende del concepto de libertad sobre el que se construye el derecho a la libertad de expresión. Dos perspectivas -ventiladas en el requerimiento de inconstitucionalidad de normas contenidas en la ley de televisión digital chilena- se enfrentan en este trabajo. La primera es una defensa de la libertad de expresión basada en la autonomía de los cuerpos intermedios y fundada en un concepto negativo de libertad. La segunda es una defensa de la libertad de expresión de corte democrático y fundada en un concepto republicano de libertad. La primera defiende la existencia de una estructura plural de medios que sea el producto del libre juego de los agentes económicos y la ausencia de interferencia estatal en los contenidos producidos. La segunda autoriza formas de regulación estructural y de contenidos en la medida en que ellas habiliten la agencia política de los ciudadanos y reduzcan los mecanismos de dominación del mercado. Del análisis de ambas posiciones el artículo concluye que la segunda garantiza de mejor forma el principio del pluralismo informativo en la televisión.

$\mathrm{PhD}$ in Law de King's College London. Profesor asociado de Derecho Constitucional de la Pontificia Universidad Católica de Valparaíso.Valparaíso, Chile.Contacto: john.charney@ pucv.cl

Recibido el 24 de octubre de 2017, aprobado el 4 de abril de 2018.

Para citar el artículo: CHARNEY BERDICHEWKY, J. Libertad de expresión y pluralismo informativo: compatibilidades y tensiones en el contexto de la televisión. En Revista Derecho del Estado, Universidad Externado de Colombia. N. . 42, enero-abril de 2019, pp. 117-148.

DOI: https://doi.org/10.18601/01229893.n42.05

**** Este artículo se enmarca en el proyecto VRIEA-PUCV 039.361/2016, en el cual el autor es el investigador principal. El autor agradece la colaboración de Karime Parodi en esta investigación y los comentarios de dos evaluadores anónimos. 
PALABRAS CLAVE

Libertad de expresión, libertad de prensa, pluralismo informativo, republicanismo, liberalismo.

\section{ABSTRACT}

The protection of media pluralism depends on the concept of liberty on which the right to free speech is grounded. Two arguments -raised during the inquiry of constitutionality of the statue that introduced digital broadcasting in Chile- are confronted in this article. The first one defends free speech on autonomy basis and is grounded on a negative concept of liberty. The second one defends free speech on democratic basis and is grounded on a republican concept of liberty. The first argument claims that a pluralistic media environment is the consequence of the free interplay of market forces and rejects media regulation. The second one authorizes media regulation as long as it enhances the political agency of citizens and reduces market domination. From this analysis the article concludes that the second argument is better enabled to guarantee the protection of broadcasting pluralism.

\section{KEYWORDS}

Freedom of speech, media freedom, media pluralism, republicanism, liberalism. SUMARIO

Introducción. 1. El requerimiento de inconstitucionalidad. 2. Diferencias conceptuales: autonomía y libertad negativa. 2.1. Libertad de expresión y dos conceptos de libertad. 3. Pluralismo y libertad. 3.1. Pluralismo externo. 3.2. Pluralismo interno. Conclusiones. Referencias.

\section{INTRODUCCIÓN}

El desarrollo y expansión de las tecnologías digitales ha producido un aumento explosivo de las plataformas comunicacionales en los últimos veinte años ${ }^{1}$. En virtud de ellas, la diversidad de opiniones, ideas y creencias existentes en una sociedad gozan de mayores oportunidades de manifestarse en la esfera pública. Lo anterior, sin embargo, no ha sido un impedimento para aumentar la intensidad regulatoria estatal con miras a

1 Para una acabada reflexión sobre la historia y consecuencias de la 'revolución' de las tecnologías de las información, ver CASTELLS, M. The Rise of the Network Society. 2. ${ }^{a}$ ed. Sussex: Wiley-Blackwell, 2010, 28-76. 
asegurar el pluralismo informativo. Un buen ejemplo es la Ley n.$^{\circ} 20.750$ que introduce la televisión digital terrestre (en adelante, TVDT) en Chile. La digitalización de la televisión supone el término (o al menos una reducción significativa) de la escasez espectral, una de las principales justificaciones de la regulación de los canales de televisión ${ }^{2}$. Al ampliar el espectro de transmisión de señales televisivas, la televisión digital disminuye las barreras de entrada al mercado televisivo, permite el ingreso de nuevos actores y crea condiciones propicias para el desarrollo del pluralismo informativo ${ }^{3}$. A pesar de esto, la ley de TVDT introdujo un conjunto de medidas regulatorias tendientes a fortalecer el pluralismo informativo y el derecho a la información. Entre otras cosas, la ley circunscribe el principio de pluralismo a una definición asociada al respeto a la diversidad; establece que los miembros del Consejo Nacional de Televisión (en adelante, CNTV) deben garantizar en su composición la observancia de este principio; amplía el número de programas respecto de los cuales el Consejo puede adoptar medidas y procedimientos tendientes a asegurar su debido respeto, e introduce normas relativas a la obligación de los canales de transmitir campañas de utilidad pública.

¿Cómo se explica que una ley que permite la introducción de plataformas tecnológicas que crean condiciones más favorables para el pluralismo informativo establezca, a su vez, mayores condiciones y limitaciones a los canales de televisión para garantizar dicho principio? Hay quienes sostienen que esto sería inconstitucional, entre otras razones, porque lesionaría la libertad de los canales de televisión de definir autónomamente sus proyectos editoriales. Por otro lado, hay quienes argumentan que dicha regulación favorece la libertad de expresión ya que a través de la transmisión de contenidos diversos se enriquecerían los procesos deliberativos de la sociedad y con ello se fortalecería la democracia. Estos argumentos fueron ventilados durante la tramitación de la ley de televisión digital, y especialmente debatidos con ocasión del requerimiento de inconstitucionalidad deducido por un conjunto de diputados en contra de algunas disposiciones de la ley ante el Tribunal Constitucional. El propósito de este artículo no es el estudio pormenorizado de la ley, sino el examen de las premisas en que estos argumentos descansan. La importancia de este análisis es que de él se siguen significados dispares sobre la libertad de expresión, sobre

2 Ver CEA, J. L. Derecho constitucional chileno. T. 2. Santiago: Pontificia Universidad Católica de Chile, 2012, 402; Bronfman, A., Martínez, J. I. y Núñez, M. Constitución Política comentada. Santiago: Legal Publishing, 2012, 283; BAREndT, E. Freedom of Speech. 2. ${ }^{\text {a }}$ ed. Oxford: Oxford University Press, 2009, 445.

3 De acuerdo a Lucas Sierra, la televisión digital es una oportunidad para aumentar la eficiencia en el uso del espectro radioeléctrico. Ver SIERRA, L. Hacia la televisión digital en Chile: historia y transición. En Estudios Públicos. Vol. 103, 2006, 111. 
el rol del pluralismo informativo en una sociedad democrática y sobre los mecanismos necesarios para tutelarlo.

La tesis que guía este análisis es que el aumento de la regulación en materia de pluralismo informativo no es necesariamente incompatible con la libertad de expresión. Por el contrario, dicha regulación puede reforzar el ejercicio de esa libertad. Este argumento que es (al menos en parte) avalado por el Tribunal Constitucional descansa en una justificación democrática de la libertad de expresión y en un concepto republicano de libertad. El argumento aquí defendido se opone a aquel que construye la libertad de expresión con base en la autonomía de los cuerpos intermedios y a un concepto de libertad como no interferencia. A partir del contraste de ambos argumentos y de las premisas sobre las que se construyen se pretende demostrar la validez de la tesis sostenida.

El artículo comienza exponiendo los principales argumentos desarrollados en el requerimiento de inconstitucionalidad del la ley de TVDT. A continuación, en una segunda sección, examina las matrices conceptuales que distinguen a ambos argumentos en cuanto a los conceptos específicos de libertad de expresión y genéricos de libertad que cada uno de ellos defiende. La sección final demuestra que un concepto republicano de libertad asociado a una defensa de la libertad de expresión de carácter democrático se encuentra en mejores condiciones para garantizar el respeto al pluralismo informativo que un concepto negativo de libertad asociado a una defensa de la autonomía de los canales de televisión como cuerpos intermedios. Se concluye señalando que mayores exigencias regulatorias en materia de pluralismo informativo no son incompatibles con la libertad cuando esta es entendida desde una perspectiva republicana y ellas están orientadas a la satisfacción de propósitos legítimos, dentro de los cuales se encuentra el respeto del principio del pluralismo informativo.

\section{EL REQUERIMIENTO DE INCONSTITUCIONALIDAD}

La Ley n. ${ }^{\circ} 20.750$, que permite la introducción de la televisión digital terrestre en Chile, muestra nítidamente el problema descrito en la introducción. En efecto, esta ley provee de un marco regulatorio para la implementación de una tecnología que permite aumentar considerablemente la capacidad espectral y con ello el número de señales televisivas disponibles al público. Al mismo tiempo, aumenta la intensidad regulatoria del Estado en materia de pluralismo informativo. La ley de TVDT fue objeto de un requerimiento de inconstitucionalidad deducido ante el Tribunal Constitucional en el que se planteó que la regulación sobre pluralismo informativo en ella contenida lesionaba el derecho a la libertad de expresión de los canales de televisión, entre otros derechos y principios constitucionales. El Tribunal consideró que dicha regulación no solo era compatible con el ejercicio de este derecho, 
sino que además lo fortalecía ${ }^{4}$. El propósito de esta sección es analizar los argumentos esgrimidos por y ante el Tribunal en el señalado requerimiento. A partir de este análisis se hace posible demostrar, más adelante, que estos argumentos descansan en premisas conceptuales sustancialmente diferentes sobre la libertad en general y sobre la libertad de expresión en particular. La relevancia de estas diferencias es que llevan a conclusiones distintas sobre el contenido del pluralismo informativo y sobre los mecanismos necesarios para tutelarlo.

El reconocimiento del principio de pluralismo en materia de televisión no es algo nuevo en el ordenamiento jurídico chileno ${ }^{5}$. Ya en 1992 la Ley n. ${ }^{\circ}$ 19.131 incorporó el pluralismo en el listado de principios y valores que los canales de televisión, a través de su programación, debían respetar y cuyo respeto el CNTV debía garantizar por mandato constitucional ${ }^{6}$. Lo que es nuevo es que la ley de TVDT refuerza este principio, dotando al CNTV de más y mejores atribuciones para garantizar su observancia ${ }^{7}$. En primer lugar, la ley define el principio del pluralismo como el respeto a la diversidad de un conjunto de dimensiones de la vida humana, tales como la social, la cultural, la étnica y la política ${ }^{8}$. En segundo lugar, la ley incrementa el número de programas respecto de los cuales el Consejo puede adoptar medidas y procedimientos

4 El requerimiento solo fue acogido respecto de la disposición contenida en la letra d) del número 1 del artículo $1 .^{\circ}$ del proyecto en la parte que establecía el deber de los canales de televisión de "excluir" aquellos contenidos que atenten contra el principio del pluralismo, por cuanto el Tribunal consideró que dicha norma constituía una forma de censura previa. STC 25412013 del 18 de noviembre de 2013.

5 La Ley n. ${ }^{\circ} 17.377$ de 1970 encargaba a la televisión universitaria la misión de "ser la libre expresión pluralista de la conciencia crítica y del pensamiento creador".

6 Para un examen detallado de la historia de la regulación de la televisión en Chile, ver SIERRA. Hacia la televisión digital en Chile: historia y transición, cit., 111-127.

7 La Constitución chilena en su artículo 19, n. ${ }^{\circ} 12$, inciso sexto, establece que el CNTV debe "velar por el correcto funcionamiento de este medio de comunicación". Por su parte, la Ley n. ${ }^{\circ} 18.838$ dispone que el correcto funcionamiento consiste en el "permanente respeto [...] de la democracia, la paz, el pluralismo, el desarrollo regional, el medio ambiente, la familia, la formación espiritual e intelectual de la niñez y la juventud, los pueblos originarios, la dignidad humana y su expresión en la igualdad de derechos y trato entre hombres y mujeres, así como el de todos los derechos fundamentales reconocidos en la Constitución y en los tratados internacionales ratificados por Chile y que se encuentren vigentes". No solo los principios, valores e instituciones contenidos en el 'correcto funcionamiento' han sido modificados a lo largo del tiempo; también lo ha sido el contenido mismo de la obligación. En efecto, el texto original de la ley del CNTV definía el 'correcto funcionamiento' como "la constante afirmación [...] de la dignidad de las personas y de la familia, y de los valores morales, culturales, nacionales y educacionales, especialmente la formación espiritual e intelectual de la niñez y de la juventud". Para garantizar el correcto funcionamiento, el Consejo está facultado para aplicar sanciones a los canales infractores, que van desde la amonestación hasta la caducidad de la concesión.

$8 \mathrm{El}$ artículo $1 .^{\circ}$, letra d), en su inciso segundo señala que "se entenderá por pluralismo el respeto a la diversidad social, cultural, étnica, política, religiosa, de género, de orientación sexual e identidad de género, siendo deber de los concesionarios y permisionarios de servicios de televisión, regulados por esta ley, la observancia de estos principios". 
destinados a asegurar su observancia. Así, a los ya tutelados programas de opinión y debate político agrega los programas de noticias. Además, la ley establece que la composición del Consejo debe garantizar adecuadamente el respeto al principio del pluralismo. La ley, a su vez, incorpora a las funciones del Consejo la de dictar normas generales y obligatorias para los canales relativas a su obligación de transmitir campañas de utilidad o interés público. Por otro lado, con el propósito de incentivar la producción regional y local, la ley permite otorgar al canal público, Televisión Nacional, una segunda concesión "que tenga por objeto la transmisión de señales de la propia concesionaria de carácter regional o de otros concesionarios que no cuenten con medios propios". Finalmente, la ley establece a los permisionarios de servicios limitados la obligación de difundir en la región o localidad en la que operen al menos cuatro canales regionales, locales o comunitarios, siempre que sea técnicamente factible.

Un grupo de 36 diputados dedujo un requerimiento de inconstitucionalidad ante el Tribunal Constitucional con el propósito de que se declarase la inconstitucionalidad de las normas indicadas en el párrafo anterior (con excepción de la que establece que la composición del Consejo debe garantizar el respeto al pluralismo). Dos líneas argumentativas, de interés para los propósitos de este artículo, fueron desarrolladas en el requerimiento. La primera de ellas consiste en que el incremento de las cargas impuesta a los concesionarios y permisionarios de servicios de televisión -principalmente la de transmitir campañas de utilidad o interés público- constituiría un atentado en contra de la igualdad ante la ley. Los requirentes sostienen, principalmente, que las obligaciones impuestas por la ley a los concesionarios y permisionarios de servicios de televisión constituyen una forma de discriminación arbitraria, toda vez que solo se aplican a los canales de televisión y no al resto de los medios de comunicación, "sin que se justifique la razón de la diferencia respecto de los demás medios existentes y posibles tecnológicamente para estos efectos" $"$. Los requirentes sostienen que la carga impuesta a los canales de televisión sería desproporcionada, puesto que otras plataformas comunicacionales como internet o la radio ejercen actualmente una influencia tanto o más importante que la televisión en la vida de las personas y, sin embargo, no están sujetas a ellas.

La segunda línea argumentativa de los requirentes se construye a partir de una trenza que incluye el principio de la subsidiariedad, la autonomía de los cuerpos intermedios y la libertad de expresión. Utilizada en cada una de las disposiciones que fueron impugnadas, esta trenza parte del supuesto de que los particulares tienen un rol prioritario en el desarrollo de las actividades económicas, sociales y culturales. La ley, al definir el principio de pluralismo, 
al imponer a los canales de televisión la obligación de respetar ese principio en parte de su programación, al obligarlos a transmitir campañas de utilidad pública, al conceder a Televisión Nacional la posibilidad de optar a una segunda concesión y al establecer una obligación a los permisionarios de servicios de televisión de difundir canales regionales, locales o comunitarios, estaría invadiendo la esfera de atribuciones propias de los particulares. Estas medidas, estiman, irían en beneficio del Estado y en perjuicio de los particulares ya que afectarían su autonomía y su libertad de expresión. Sin hacer una distinción conceptual nítida entre autonomía y libertad de expresión, los requirentes sostienen que las medidas impugnadas afectan la capacidad de los canales de definir por sí mismos sus líneas editoriales (más adelante se verá que la falta de distinción conceptual de los requirentes entre libertad y autonomía es característica de una matriz teórica bien definida). Por otro lado, los requirentes sostienen que desde el momento en que la ley define el principio del pluralismo y señala taxativamente cuáles son las categoría que este principio obliga a respetar, al paso que deja fuera otras (como la nacionalidad, la situación socioeconómica, la edad, la apariencia), se están aumentando "los poderes de control de la autoridad pública sobre la libertad y la autodeterminación de las personas, pues sería aquélla la que determinaría qué es lo que puede ser considerado digno de ser protegido o reconocido en el contexto de una sociedad plural" ". Desde este punto de vista la ley no solo afectaría la autonomía y libertad de los canales de televisión sino, además, la de las audiencias en general.

Bajo los mismos argumentos, los requirentes alegan la inconstitucionalidad de las atribuciones conferidas al CNTV para fijar las directrices sobre las campañas de utilidad pública así como los mecanismos diseñados por la ley para el estímulo de la producción regional y local. Sobre la base del principio de subsidiariedad, señalan que el Estado estaría invadiendo la autonomía y libertad de los canales de televisión para definir, por sí mismos, la manera de organizar su programación y los objetivos que desean alcanzar a través de sus líneas editoriales. Asimismo, estaría lesionado el derecho a la libre iniciativa económica de los permisionarios de servicios de televisión, toda vez que se les obliga a difundir canales regionales, locales o comunitarios. La intervención estatal en la autonomía de los concesionarios y permisionarios de servicios de televisión constituiría, según los requirentes, un atentado en contra de la libertad de expresión ya que el Estado estaría imponiendo cargas y obligaciones que vulneran el derecho de los canales de decidir libremente los contenidos que transmiten de acuerdo a sus líneas editoriales, así como de rechazar aquellos que consideren contrarios a las mismas. 
El Tribunal Constitucional rechaza, en general, los argumentos defendidos por los requirentes. Sobre la igualdad ante la ley, sostiene que la televisión tiene características que la diferencian del resto de los medios de comunicación social y que justificarían un tratamiento regulatorio diferenciado ${ }^{11}$. La primera de ellas sería su influencia en la sociedad. El Tribunal señala que "la televisión misma aspira a ser ella el espejo de la sociedad que proyecta, para lo cual refuerza su vínculo amplio con las audiencias" ${ }^{12}$. El fallo agrega que el consumo de televisión es muy alto, penetra en todos los sectores sociales e impacta más que la prensa escrita ${ }^{13}$. La segunda característica de la televisión que justificaría un tratamiento diferenciado sería el hecho de que utiliza el espectro radioeléctrico que es un bien nacional de uso público, el que, según el propio Tribunal, es "por definición limitado" ${ }^{14}$.Por esta razón, su uso debe ser objeto de una concesión otorgada por el Estado, y en su otorgamiento se pueden imponer condiciones a los concesionarios que no podrían imponerse, por ejemplo, a la prensa escrita, la que no depende de un bien nacional de uso público para su funcionamiento ${ }^{15}$.

Las particularidades de la televisión explican por qué históricamente ha sido sometida, desde un punto de vista normativo, a un trato diferenciado. Distinciones que se manifiestan en primer lugar en materia de titularidad. En efecto, tratándose de la televisión, su titularidad es restringida. La ley solo la reconoce respecto de personas jurídicas de derecho público o privado, y no respecto de personas naturales o personas jurídicas constituidas en el extranjero. En segundo lugar, la televisión, a diferencia de otros medios de comunicación, se encuentra bajo la supervigilancia del cNTV cuya función, de acuerdo a la propia Constitución, es la de "velar por el correcto funcionamiento de este medio de comunicación". El cNTv tiene la facultad de imponer sanciones en caso de que los canales infrinjan sus deberes, sanciones que

11 Este argumento ya había sido esgrimido por el Tribunal en STC 56-88 de 9 de agosto de 1988 y stc $2487-13$ de 20 de junio de 2013.

12 STC 2541-13 de 18 de noviembre de 2013, considerando vigésimo.

13 Este argumento ha sido esgrimido, entre otros, por por Brunner y Catalán, y en la medida en que la televisión ha perdido su influencia en relación con otros medios o plataformas de comunicación el argumento se ha vuelto problemático. Si el resto de los medios se vuelven tan influyentes como la televisión, ¿debiesen también ser objeto del tipo de regulación que se le aplica a la televisión? Sunstein, por su parte, sostiene que es la influencia que los medios de comunicación (en general) tienen en el proceso deliberativo lo que justificaría la regulación estatal. Ver Brunner, J. J. y Catalán, C. Televisión, libertad, mercado y moral. Santiago: Los Andes, 1995; Sunstein, C. Democracy and the Problem of Free Speech. New York: The Free Press, 1995, 17-23.

14 STC 2541-13 de 18 de noviembre de 2013, considerando vigésimo.

15 Si bien el servicio radial también es un servicio de difusión que utiliza un bien nacional de uso público para sus transmisiones, no se encuentra sujeta a la carga regulatoria de la televisión. Según Sierra, lo anterior se debe a que la radio, a diferencia de la televisión, siempre fue iniciativa de privados. Ver Sierra. Hacia la televisión digital en Chile: historia y transición, cit., 118 . 
pueden llegar hasta la caducidad de la concesión. Finalmente, la televisión tiene obligaciones legales, como la transmisión gratuita de la franja para campañas políticas en periodo de elecciones presidenciales y parlamentarias, obligaciones que el resto de los medios de comunicación no deben soportar.

Despejado el punto sobre la igualdad ante la ley y clarificadas las particularidades que justificarían un tratamiento diferenciado, el Tribunal desarrolla el argumento que explica la compatibilidad de las medidas impugnadas con la autonomía de los canales y la libertad de expresión. El argumento se puede dividir en dos partes. En primer lugar, el Tribunal destaca el carácter instrumental de la libertad de expresión: esta cumple un rol fundamental en el sistema democrático toda vez que hace posible el debate de ideas sobre los temas que afectan la vida en común. La libertad de expresión, por lo mismo, es necesaria para alcanzar una ciudadanía informada, lo que constituye un presupuesto básico para el correcto funcionamiento de un gobierno que opera sobre la base de la deliberación y el enfrentamiento de ideas ${ }^{16}$. La libertad de expresión, de acuerdo al Tribunal, no solo tiene una dimensión individual referida al sujeto activo, es decir, a quien profiere opiniones o expresiones en la esfera pública. También tiene una dimensión colectiva ${ }^{17}$. Esta última se refiere a los sujetos pasivos, a los destinatarios de la información, expresiones y opiniones que se vierten en la esfera pública. La libertad de expresión, desde esta dimensión, protege el derecho de los ciudadanos a informarse debidamente. Es ella la que justifica, de acuerdo al Tribunal, las cargas impuestas a los canales de televisión de transmitir información que beneficie al público cuando están en juego los intereses superiores de sociedad. Así, el Tribunal señala "que [el] titular privilegiado y último de la libertad de información, es la persona que la recibe; el medio es sólo un instrumento" 18 . Los medios de comunicación, al ser un instrumento -y no un fin en sí mismo- deben soportar medidas regulatorias destinadas a la satisfacción de intereses superiores.

Además de defender la libertad de expresión desde una perspectiva democrática, el Tribunal rechaza que las medidas contenidas en la ley de TVDT afecten la autonomía de los canales de televisión. En primer lugar, establece, en términos generales, que no existe una incompatibilidad entre la autonomía

16 De acuerdo a Barendt, la defensa a la libertad de expresión como un mecanismo de fortalecimiento del sistema democrático ha sido ampliamente aceptada por los tribunales de justicia en las democracias liberales. Ver B ARENDT, E. Freedom of Speech.2. ${ }^{a}$ ed. Oxford: Oxford University Press, 2009, 18. Tanto el Tribunal Constitucional (sTC 567-10 de 3 de junio de 2010) como la Corte Suprema (Rol 6944-2015, de 30 de septiembre de 2015) han manifestado la importancia de la libertad de expresión en el correcto funcionamiento del sistema democrático.

17 Para una defensa de la libertad de expresión como un bien público, ver Raz, J. Free Expression and Personal Identification. En Oxford Journal of Legal Studies. Vol. 11, n. ${ }^{\circ} 3,306-$ 309.

18 STC 2541-13 de 18 de noviembre de 2013, considerando vigesimotercero. 
de los canales y la regulación legal: "Desde luego, porque la potestad legislativa tiene rango constitucional. El legislador está llamado a dictar normas generales y obligatorias. Por lo mismo, cuando cumple esa tarea, no realiza por ese solo hecho una intromisión ilegítima en dicha autonomía. Los grupos intermedios no están al margen de los mandatos del legislador" ${ }^{19}$. Además, la televisión, por sus especiales características, no puede ser catalogada como un grupo intermedio cualquiera ${ }^{20}$. Por el contrario, la televisión, tal como lo señala el Tribunal, es fundamental para el funcionamiento adecuado del sistema democrático, y por lo mismo se justifica la existencia de legislación que oriente su actuar hacia la consecución de sus fines específicos.

\section{DIFERENCIAS CONCEPTUALES: AUTONOMÍA Y LIBERTAD NEGATIVA}

Es posible advertir una serie de diferencias conceptuales entre el argumento de los requirentes y el desarrollado por el Tribunal Constitucional. Estas diferencias se enmarcan en estructuras teóricas más complejas que responden a concepciones distintas sobre el contenido y el propósito de la libertad y de los derechos. Mientras el argumento de los requirentes se ajusta a las matrices del pensamiento liberal, el argumento del Tribunal responde a las matrices del pensamiento republicano. El objetivo de esta sección es aclarar estas diferencias e identificar las concepciones sobre el pluralismo informativo y los mecanismos idóneos y necesarios para obtener su tutela que cada una de estas aproximaciones defiende.

La primera diferencia relevante está dada por el concepto de autonomía que utilizan una y otra. Desde un determinado sector de la tradición liberal, la autonomía requiere de la capacidad de pensar y de actuar sin interferencia indebida por parte de agentes externos ${ }^{21}$. La autonomía no se limita al individuo sino que también puede reconocerse a los grupos intermedios, como los canales de televisión o la prensa escrita. Así lo hace la Constitución chilena cuando les garantiza, en su artículo $1 .^{\circ}$, la adecuada autonomía para cumplir sus fines específicos ${ }^{22}$. Por lo mismo, y desde esta perspectiva, el Estado, al

19 Ibíd., considerando vigesimonoveno.

20 Ibíd., considerando trigésimo. El Tribunal Constitucional ya había señalado el carácter especial de los canales de televisión como cuerpos intermedios de la sociedad en STC 2487-13 de 20 de junio de 2013.

21 Para un desarrollo conceptual de la autonomía personal en relación con la libertad de expresión ver, en especial, SCANLon, T. Freedom of Expression and Categories of Expression. En University of Pittsburgh Law Review. Vol. 40, 1979, 519; DworkIn, R. The coming Battles over Free Speech. En The New York Review of Books. 11 de junio de 1992.

22 En este sentido, el voto minoritario en el fallo sobre el requerimiento de constitucionalidad del proyecto de TVDT sostiene que "a los medios de comunicación social, en su carácter de cuerpos intermedios de la sociedad, la Constitución -en las Bases de la Institucionalidadles garantiza la adecuada autonomía para cumplir sus fines específicos”. STC 2541-13 de 18 de noviembre de 2013, párr. 12 . 
definir el concepto de pluralismo en la ley de TVDT y delimitar su ámbito de protección, limita la autonomía de los canales privados ya que les impide definir por sí mismos y de acuerdo a sus líneas editoriales las categorías que cabrían dentro del ámbito de protección del pluralismo. Esto equivaldría a una forma de control estatal de los contenidos que vulneraría la autonomía de los canales de televisión. Desde este punto de vista, la forma adecuada de garantizar el pluralismo informativo es a través de la existencia de una pluralidad de medios de comunicación, donde cada uno, al tener su propia línea editorial, contribuiría a configurar un sistema que, en su conjunto, representaría la totalidad (o un número significativo) de las visiones e ideas existentes en la sociedad ${ }^{23}$. Esto es lo que la doctrina ha denominado pluralismo externo, por oposición al pluralismo interno, mediante el cual todos los medios deben respetar en su programación (o en parte de ella) el principio del pluralismo informativo ${ }^{24}$.

Este argumento tiene dos grandes problemas. El primero, que se considera con más detalle en la siguiente sección, es que (a) asume que la pluralidad de controladores produce diversidad de contenidos, cuando existe evidencia que permite concluir precisamente lo contrario, y (b) es con base en ese supuesto controvertido que valora la diversidad en la propiedad de los medios de comunicación (cuando el pluralismo estructural tiene un valor en sí mismo). De (b) se sigue un tercer problema, ya que si la pluralidad en la propiedad de los medios de comunicación se defiende en virtud de argumentos consecuencialistas, tales como que ella maximiza la diversidad de contenidos informativos, y esas consecuencias no se producen en la práctica, entonces la defensa de la pluralidad de la propiedad de los medios se desmorona.

El segundo problema del argumento es que confunde autonomía con libertad negativa, cuando son dos conceptos distintos. Libertad negativa, de acuerdo a Isaiah Berlin, es la ausencia de interferencia externa en el ámbito de acción de un agente. Por ello, la libertad de un agente es restringida cuando este es impedido, por la acción de un tercero, de hacer algo que de otra forma podría haber hecho ${ }^{25}$. Si para los efectos del argumento, y solo para tales efectos, se acepta esta definición de la libertad, se podría decir, sin mayores problemas, que la definición de pluralismo dada por la ley limita la libertad de los canales

23 En el requerimiento sobre inconstitucionalidad de la ley de TVDT, los requirentes sostienen: "la mejor manera de fomentar la libertad y el pluralismo en los medios de comunicación está asociada a la posibilidad de que existan distintos medios, tanto en tipo como en orientación". STC 2541-13 de 18 de noviembre de 2013, 3.

24 Ver Hallin, D. y Mancini, P. Comparing Media Systems: Three Models of Media and Politics. Cambridge: Cambridge University Press, 2004, 29-30; Hrtchens, L. Broadcasting Pluralism and Diversity: A Comparative Study of Policy and Regulation. Oxford: Hart Publishing, 2006, 6 .

25 Un hombre es libre desde una perspectiva negativa, según Berlin, en la medida en que ningún otro hombre u objeto interfiera en su actividad. BerLIN, I. Two Concepts of Liberty. En HaRdy, H. Liberty. Oxford: Oxford University Press, 2002, 169. 
de obviar, si así lo desean, el respeto a las categorías de diversidad protegidas en ella. La ley, en otras palabras, limita el ámbito de acción de los canales de televisión en cuanto les prohíbe vulnerar el principio de pluralismo en los programas políticos y de noticias. La pregunta que es pertinente formularse, a estas alturas, es si esto constituye, además, una limitación en la esfera de la autonomía de los canales de televisión. Para responder esta pregunta es necesario identificar en qué consiste la autonomía.

La autonomía, tal como lo ha señalado una abundante literatura, es la capacidad que se le reconoce a un agente de darse a sí mismo las normas que lo regulan, es decir, de ser autor de sus planes y proyectos de vida ${ }^{26}$. Según Christman, un elemento central de cualquier concepción de autonomía es la capacidad de auto-legislarse, es decir, de actuar, reflexionar y decidir a partir de factores que son propios ${ }^{27}$. En un sentido similar, Waldron señala que la autonomía requiere de un tipo de deliberación auto-reflexiva ${ }^{28}$. Una decisión es autónoma, desde este punto de vista, cuando ella es el resultado de un diálogo que un agente tiene consigo mismo. La principal diferencia entre autonomía y libertad consiste entonces en que la primera contiene un proceso de deliberación interno que está ausente o que no es necesario en la segunda. Por lo mismo, una medida determinada puede afectar la libertad de un agente sin dañar su autonomía cuando ella (a) no afecta el proceso auto-reflexivo que caracteriza a la autonomía o bien cuando (b) refuerza dicho proceso. Por ejemplo, cuando Ulises pide a sus tripulantes que lo aten al mástil del barco para no dejarse seducir por el canto de las sirenas a riesgo de abandonar la expedición, y los tripulantes así lo hacen, Ulises ve privada su libertad, mas no su autonomía. Y es que la restricción a la libertad de Ulises es la que le permite gobernarse por sus propios deseos, y no por el de las sirena ${ }^{29}$. Ahora bien, si la autonomía es un proceso auto-reflexivo que supone un diálogo de un agente consigo mismo, es indispensable identificar en qué consiste aquello con lo que un agente dialoga para calificar una decisión como autónoma. Cuando se trata de la autonomía de cuerpos intermedios, la Constitución en su artículo $1 .^{\circ}$, inciso tercero, facilita esta tarea. En efecto, lo que la Constitución garantiza a estos grupos es "la adecuada autonomía para cumplir sus

26 Para un influyente estudio sobre la autonomía personal, ver DworkIn, G. Autonomy and Behavior Control. En Hasting Center Report. Año 6 n. ${ }^{\circ}$ 1, 1976, 34-47.

27 Ver Christman, J. Autonomy in Moral and Political Philosophy. En Stanford Encyclopedia of Philosophy. 2011. Disponible en: https://plato.stanford.edu/archives/spr2011/entries/ autonomy-moral/ (Consultado el 20 de octubre de 2017).

28 Ver Waldron, J. Moral Autonomy and Personal Autonomy. En Christman, J. P. y Anderson, J. Autonomy and the Challenges to Liberalism. Cambridge: Cambridge University Press, 2005, 307.

29 En su famoso ensayo Ulysses and the Syrens (1979), Jon Elster utiliza este ejemplo sacado de La Odisea para explicar la constitución como un instrumento de resguardo frente a impulsos irracionales del demos. Para una exposición más actualizada, véase ELSTER, J. Ulysses Unbound. Cambridge: Cambridge University Press, 2000. 
propios fines específicos". Se destaca la última parte de la disposición puesto que ella indica que la autonomía de los grupos intermedios se determina con base en las características particulares de cada grupo, es decir, en relación a sus finalidades específicas. De esto se siguen algunas consecuencias.

La autonomía de los canales de televisión no puede ser, en primer lugar, equivalente a la autonomía de otros grupos intermedios, ya que la autonomía de cada uno se determina a partir de sus propios fines específicos ${ }^{30}$. De esto se sigue que la autonomía de los canales de televisión solo puede ser entendida en relación a la institución particular que son los canales de televisión ${ }^{31}$. Y la televisión, tal como lo ha indicado el Tribunal Constitucional ${ }^{32}$, así como lo ha hecho insistentemente la jurisprudencia nacional e internacional ${ }^{33}$, juega un rol fundamental en el proceso democrático. En efecto, la televisión no solo cumple un rol esencial al facilitar la discusión y deliberación sobre los asuntos de relevancia pública, sino que además permite amplificar las distintas voces, opiniones y expresiones existentes en una comunidad política. Por esta razón, aquellas medidas que tengan por objeto reforzar el derecho de los canales de televisión de definir sus líneas editoriales sobre la base de factores que les son propios, es decir, aquellos que buscan fortalecer sus propios fines específicos, no pueden constituir una restricción a su autonomía.

Libertad negativa y autonomía son, en conclusión, conceptos distintos. Si la libertad negativa es la falta de interferencia en el ámbito de acción individual o colectivo, la autonomía es la capacidad de decidir en virtud de factores que son propios. A partir de esta diferencia se puede afirmar razonablemente que si bien una interferencia externa en el ámbito de acción de un agente puede constituir una restricción a su libertad negativa, no necesariamente constituye una restricción a su autonomía. Cuando estas distinciones se pasan por alto, se corre el riesgo de confundir restricciones a la libertad negativa con restricciones a la autonomía. Eso es precisamente lo que sucede cuando se sostiene que la delimitación de ciertas categorías a las que la programación de los canales de televisión debe respeto, por ser ellas manifestaciones de la diversidad de los seres humanos (como su posición social, cultural, étnica, orientación sexual, etc.), sería un atentado en contra de la autonomía de los

30 Por lo mismo, salta a la vista el despropósito de que la televisión, así como el resto de los medios de comunicación, sea tratada como un negocio más, como lo sugiere Mark Fowler, ex director de la Federal Communications Commission (FCC) cuando afirma que "la televisión es solo un artefacto más. Es una tostadora con imágenes".

31 Lo mismo puede decirse de las universidades; véase, al respecto, Atria, F. Autonomía universitaria y universidad pública. 2016. Disponible en: http://www.elmostrador.cl/noticias/ pais/2016/11/01/autonomia-universitaria-y-universidad-publica (Consultado el 20 de octubre de 2017).

32 STC 2541-13 de 18 de noviembre de 2013, considerando vigesimotercero; sTC 567-10 de 3 de junio de 2010 .

33 Ver Fenwick, H. y Phillipson, G. Media Freedom under the Human Rights Act. Oxford: Oxford University Press, 2006, 16. 
canales de televisión. Lo que hace la ley es definir un piso normativo mínimo sobre los modos de comunicación aceptables en una sociedad diversa que se aplican a un número puntual y específico de programas televisivos, como lo son los programas de debate político y los programas de noticias. Estas medidas no afectan la autonomía de los canales de televisión puesto que la ley ajusta sus líneas editoriales a ciertos criterios mínimos de aceptabilidad en las comunicaciones que se dan en una sociedad diversa y que los canales de televisión, por la función específica que desempeñan en el sistema democrático, están llamados a respetar.

\subsection{Libertad de expresión y dos conceptos de libertad}

Una segunda diferencia conceptual entre las posiciones descritas en los párrafos anteriores surge de la combinación entre las justificaciones de la libertad de expresión que cada una de ellas defiende, por una parte, y, por la otra, los conceptos de libertad sobre los que construyen dichas justificaciones. Para identificar (con algún grado de precisión) los matices de esta segunda diferencia es necesario aclarar que ella opera en dos niveles distintos. Mientras las justificaciones de la libertad de expresión se refieren a la libertad en un sentido o ámbito concreto de su aplicación (el de la expresión), los conceptos de libertad se refieren a ella de manera general o a nivel de principios. Como se analiza en esta sección, la literatura no solo ha proporcionado distintas justificaciones de la libertad de expresión (como la de la verdad, la democrática y la de la autonomía) $)^{34}$, sino también distintos conceptos de libertad (como el liberal y el republicano). Estos niveles pueden combinarse de distintas maneras, de modo que es posible, por ejemplo, encontrar defensas de la libertad de expresión basadas en el argumento de la verdad que utilizan el concepto republicano de libertad ${ }^{35}$, como otras que utilizan uno liberal ${ }^{36}$. De las posiciones enfrentadas ante el Tribunal Constitucional chileno a propósito del requerimiento de inconstitucionalidad de la ley de televisión digital aparecen dos combinaciones de las categorías referidas. Por un lado, el Tribunal defiende la libertad de expresión desde una justificación democrática articulada sobre la base de un concepto de libertad republicano (no dominación). Los requirentes, por otro lado, defienden la libertad de expresión desde la justificación de la autonomía de los canales de televisión, y lo hacen sobre la base de un concepto liberal de libertad (no interferencia). Lo que interesa demostrar aquí es que los conceptos de libertad bajo los cuales

34 Veáse BARENDT, E. Freedom of Speech. 2. ed. Oxford: Oxford University Press, 2009 y BAKER, E. Human Liberty and Freedom of Speech. New York: Oxford University Press, 1993.

35 Como es el caso de Mitton, J. Areopagitica. Champaign, IL.: Standard Publications, 2008.

36 Como sucede con Mitl, J. S. On Liberty. New York: Cosimo Classics, 2005. 
estos argumentos articulan sus defensas de la libertad de expresión tienen consecuencias en (a) la relevancia que atribuyen a la estructura en la que se enmarca la formación de la opinión pública en una sociedad democrática, y (b) la relación entre el ordenamiento jurídico y la libertad individual. En esta sección se analizan brevemente las justificaciones de la libertad de expresión relevantes para esta discusión, así como los conceptos de libertad sobre los que ellas se construyen. En la sección que sigue se ve que estas diferencias son relevantes para entender el modo en que cada uno de estos argumentos entiende lo que es el pluralismo informativo y los medios adecuados para tutelarlo.

La justificación democrática de la libertad de expresión, asociada generalmente a la tradición republicana ${ }^{37}$, tiene múltiples versiones ${ }^{38}$. Todas ellas, sin embargo, coinciden en que la libertad de expresión es un mecanismo indispensable para asegurar el debido funcionamiento del proceso democrático. Esto se debe, según sostienen algunos, a que el ejercicio de esta libertad es garantía de una ciudadanía informada, presupuesto fundamental del autogobierno-colectivo ${ }^{39}$. Para otros, la libertad de expresión ejercida a través de una prensa libre es un mecanismo de control de la autoridad política que permite reducir los abusos de poder y por ello es una garantía de buen gobierno ${ }^{40}$. Por último, hay quienes sostienen que la libertad de expresión es una herramienta que facilita el vínculo comunicativo entre la sociedad civil y el poder político. De este modo, su ejercicio permite a los ciudadanos participar activamente en el proceso político y en la deliberación de los asuntos de relevancia colectiva ${ }^{41}$. Con independencia de su versión, el argumento democrático refuerza el derecho a la información y, por sobre cualquier otra consideración, reafirma su relevancia en el ejercicio de las libertades políticas.

37 Veáse, en especial, Meiklejonn, A. Free Speech and its Relation to Self-Government. En Meiklejohn, A., Political Freedom: The Constitutional Power of the People. New York: Oxford University Press, 1965 y SunsteIn. Democracy and the Problem of Free Speech, cit.

38 Esta es la que defendió el Tribunal Constitucional en el requerimiento de inconstitucionalidad del proyecto de TVDT al señalar que "la libertad de expresión desempeña un papel fundamental en la sociedad democrática, pues permite el debate de ideas, el intercambio de puntos de vista, emitir y recibir mensajes, la libre crítica, la investigación científica, el debate especulativo, la creación artística, el diálogo sin restricción, censura ni temor y la existencia de una opinión pública informada". STC 2541-13 de 18 de noviembre de 2013, considerando decimosexto.

39 Este es el clásico argumento de Meiklejohn, quien es considerado uno de los principales exponentes de la justificación democrática de la libertad de expresión; ver MeIKLEJoHN. Free Speech and its Relation to Self-Government, cit.

40 Este argumento fue articulado brillantemente por Bentham, J. On the Liberty of the Press. En Bowring, J., The Works of Jeremy Bentham. Edinburgh: William Tait, 1843. Una versión más reciente es la de Blasi, V. The Checking Value in First Amendment Theory. En American Bar Foundation Research Journal. Año 2, n. ${ }^{\circ}$ 3, 2004, 521-649.

41 Una original aproximación a este argumento es la que ofrece Post, R. Participatory Democracy and Free Speech. En Virginia Law Review. Vol. 97, n. ${ }^{\circ}$ 3, 2011, 477-489. 
El argumento de la autonomía en materia de libertad de expresión, por otro lado, ha sido defendido por autores liberales como Scanlon, Dworkin y $\mathrm{Raz}^{42}$. Todos ellos rescatan la importancia del desarrollo de la agencia moral de los individuos. Ven en la libertad de expresión una herramienta que permite a las personas manifestar abiertamente sus convicciones, creencias y estilos de vida en la esfera pública. La libertad de expresión, desde esta perspectiva, se valora no porque contribuya al debate y a la deliberación pública, sino porque permite la autoafirmación de la personalidad y de la identidad individual. Si bien este argumento tiene influencia en la defensa de la libertad de expresión como un derecho individual, es necesario decir que es problemático cuando se lleva al terreno de los medios de comunicación, como lo hicieron los diputados que requirieron la inconstitucionalidad del proyecto de ley de televisión digital ante el Tribunal Constitucional chileno ${ }^{43}$. Tal como ha afirmado O'Neill, es un error categorial trasladar el argumento de la autonomía del terreno de los derechos individuales al de los medios de comunicación. De estos últimos no se esperan actividades auto-expresivas. Por el contrario, se espera que comuniquen información relevante para la vida en común y que lo hagan en modos que sean inteligibles para todos. $\mathrm{Su}$ deber es proporcionar herramientas que permitan a los ciudadanos hacer juicios correctos sobre la realidad social ${ }^{44}$. Por razones distintas, Baker llega a conclusiones similares a las de O'Neill. Baker, que defiende la libertad de expresión a nivel individual desde el argumento de la autonomía, sostiene que este argumento no puede utilizarse para defender la libertad de prensa. Los medios de comunicación, sostiene, están guiados por fines comerciales. Por lo mismo, los contenidos que transmiten no son el producto de su autoexpresión, sino de fuerzas heterónomas que están orientadas a maximizar su utilidad económica. A pesar de lo anterior, la prensa debe ser protegida, y debe serlo por las especiales características de los contenidos que produce. Contenidos que, desde la perspectiva de Baker, permiten el control de la autoridad política en beneficio de los ciudadanos ${ }^{45}$.

42 Para un análisis del conjunto de defensas a la libertad de expresión articuladas en torno a la autonomía ver, Brison, S. The Autonomy Defense of Free Speech. En Ethics. Vol. 108, n. ${ }^{\circ}$ 2,312-339.

43 Tal como sucedió a propósito del requerimiento de inconstitucionalidad del proyecto de ley de TVDT en el que los requirentes sostienen que, "de entrar en vigencia el precepto impugnado, los canales de televisión deberán dar cuenta a la autoridad de que han promovido activamente el pluralismo [...] lo que supone una intervención en la línea editorial de los canales, infringiéndose así flagrantemente la libertad de informar y emitir opiniones". STC 2541-13 de 18 de noviembre de 2013, 11 .

44 Ver O'NeILl, O. News of this World. En Financial Times. 18 de noviembre de 2011. Disponible en: https://www.ft.com/content/25c0d316-0ec6-11e1-9dbb-00144feabdc0, (Consultado el 20 de octubre de 2017).

45 BAKER, E. Human Liberty and Freedom of Speech. New York: Oxford University Press, 1993, 229. 
Los contrastes entre las justificaciones de la libertad de expresión aquí presentados suelen agudizarse cuando se analizan a la luz de los conceptos de libertad afines a estas teorías. Pues en efecto, mientras la versión democrática de la libertad de expresión tiende a descansar en un concepto republicano de libertad ${ }^{46}$, la versión asociada a la autonomía lo hace sobre un concepto de libertad como no interferencia ${ }^{47}$. Desde una perspectiva republicana, la libertad solo puede existir en una comunidad políticamente organizada y solo puede ejercerse en el vínculo que une a un individuo con esa comunidad ${ }^{48}$. Un agente solo puede ser libre, desde esta perspectiva, en la medida en que las estructuras en las que se enmarcan las relaciones sociales y políticas impidan la dominación de unos sobre otros. En consecuencia, la ley como instrumento regulador de tales relaciones es fundamental para garantizar la libertad ${ }^{49}$. Por otro lado, el concepto de libertad como no interferencia, asociado al liberalismo, entiende que la libertad es anterior al pacto político y que el propósito de este último es resguardarla frente al ejercicio del poder político. La libertad, desde esta perspectiva, comienza allí donde la política termina. Por lo mismo, mientras menor sea el espacio de la política, mayor será la esfera de la libertad. Desde este punto de vista, la ley es siempre considerada como una potencial amenaza a las libertades individuales.

La distinción entre un concepto republicano de libertad -sobre el cual se construye usualmente la defensa democrática de la libertad de expresión-, por un lado, y un concepto liberal de libertad -sobre el que usualmente se construye la defensa de la libertad de expresión basada en la autonomía-, por el otro, tiene consecuencias relevantes para los propósitos de este artículo. Tal como se adelantó, estos conceptos conducen a conclusiones distintas sobre (a) la relevancia de las estructuras en las que se enmarca el proceso

46 Veáse supra n. 37

47 En su ya clásico ensayo "Dos conceptos de libertad", Berlin distingue, siguiendo a Constant, un concepto antiguo o positivo de libertad de un concepto moderno o negativo de libertad. Ver BerLIN. Two Concepts of Liberty, cit., 168-169. Pettit agrega un tercer concepto de libertad a la ya tradicional distinción: la libertad republicana, que es equivalente a la ausencia de dominación. Pеттাт, P. Republicanism: A Theory of Freedom and Government. Oxford: Oxford University Press, 1997, 21-27. Para justificaciones de la libertad de expresión basadas en la autonomía individual y que se construyen sobre la base de un concepto de libertad como no interferencia, véase Dworkin. The coming Battles over Free Speech, cit.; SCANLON, T. Freedom of Expression and Categories of Expression. En University of Pittsburgh Law Review. Vol. 40, 1979, 519.

48 Este es el concepto de libertad que defiende ArEndt, H. Freedom and Politics. En MilLER, D. The Liberty Reader. Edinburgh: Edinburgh University Press, 2006, 58-70.

49 Loughlin habla de la gramática del derecho público para explicar que, así como las reglas de la gramática no son restricciones del lenguaje sino mecanismos que permiten hablar con mayor precisión, las reglas y normas de derecho público no deben ser entendidas como restricciones o limitaciones a la libertad o al poder sino como reglas constitutivas del significado de esos términos. Ver Loughlin, M. Foundations of Public Law. Oxford: Oxford University Press, $2010,178$. 
de formación de la opinión pública y (b) la relación entre libertad y ordenamiento jurídico. En lo que queda de esta sección se analizan los motivos que explican estas diferencias, y en la siguiente, la influencia que ellas tienen en la relación entre pluralismo informativo y libertad de expresión.

De acuerdo a Pettit, mientras la libertad liberal es la ausencia de interferencia externa en el ámbito de la acción individual o colectiva, la libertad republicana es la ausencia o falta de dominación. Ambos conceptos son distintos ya que interferencia es, a su vez, un concepto distinto del de dominación. Por lo mismo, puede haber formas de interferencia que no signifiquen dominación, así como formas de dominación que no impliquen interferencia ${ }^{50}$. Tal vez el modo más claro para entender esto (y ahorrarse disquisiciones analíticas) sea remontarse a los hechos históricos que generaron el 'descubrimiento' del concepto de libertad como no interferencia ${ }^{51}$. Este último surge en un contexto muy particular. Durante la guerra civil inglesa, a mediados del siglo XVII, Thomas Hobbes reacciona en contra del ímpetu revolucionario impulsado por el movimiento republicano. De acuerdo a Hobbes, los republicanos habían sido responsables de promover una ideología que había sido la causa de la guerra y del derramamiento de tanta sangre. Dicha ideología había sido heredada del pensamiento de los antiguos, y en particular, del modo en que ellos comprendían el concepto de libertad. La libertad de los atenienses, aquella que fue defendida en La Política por Aristóteles, legada a Cicerón y exaltada por los enemigos de Hobbes, es un concepto político de libertad que, de acuerdo a este último, se refiere al soberano y no al individuo ${ }^{52}$. Esta libertad consiste en la falta de sujeción a la voluntad de otro, es decir, en la capacidad de autogobierno o, si se quiere, en la ausencia de dominación. La libertad, desde esta perspectiva, solo es posible cuando se cumplen ciertas condiciones políticas; condiciones que permiten el autogobierno colectivo. Es por ello que este concepto de libertad es afín a formas democráticas de gobierno e incompatible -por supuesto- con la monarquía absoluta. Este concepto -que Hobbes se propone erradicar del ideario político- es el que

50 Pettit ilustra la relación entre interferencia y dominación con el ejemplo del amo y el esclavo. En esta relación el amo puede interferir arbitrariamente en las decisiones y opciones del esclavo, sin embargo, dicha interferencia no es esencial en esta relación. El amo benevolente que permite al esclavo hacer todo aquello que estime conveniente representa una figura paradigmática de dominación sin interferencia. Si puede haber dominación sin interferencia, también puede haber interferencia sin dominación. Esto puede ocurrir, de acuerdo a Pettit, cuando un agente interfiere en mi órbita de acción bajo la condición que lo haga en mi propio interés y con base en principios o reglas que comparto. La ley es un clásico ejemplo de interferencia sin dominación. Ver Petтit. Republicanism: A Theory of Freedom and Government, cit., 22-27.

51 Para un análisis en profundidad sobre el surgimiento del concepto negativo de libertad en la obra de Hobbes véase SKInNER, Q. Hobbes and Republican Liberty. Cambridge: Cambridge University Press, 2008, 82-177.

52 Hobbes, T. Leviathan. London: Penguin Classics, 1985, 266. 
inspira la temprana revolución republicana en Inglaterra, la cual llevaría a la ejecución de Carlos I y a la instauración del protectorado de Oliver Cromwell.

Frente al concepto político de libertad, defendido por los republicanos, Hobbes propone un concepto distinto: un concepto que apela a la libertad del individuo y no a la del soberano. El hombre libre, de acuerdo a Hobbes, "is he, that in those things, which by his strength and wit he is able to do, is not hindred to doe what he has a will to" ${ }_{53}$. A diferencia del concepto republicano de libertad, el que defiende Hobbes se concentra en la interferencia real y directa por medio de un agente externo en la esfera de acción individual. Desde este punto de vista, la libertad individual solo es restringida cuando la acción de un tercero impide que una persona pueda realizar aquello que desea hacer. El concepto de libertad del filósofo contractualista es perfectamente compatible con la sujeción de la voluntad individual e incluso con la dominación por parte de otro, en la medida en que dicha sujeción o dominación no constituya un impedimento o restricción a la acción individual. Este concepto de libertad permite a Hobbes justificar formas de gobierno absoluto, al mismo tiempo que rechazar, por superflua, la idea de que las republicas aseguran la libertad de sus ciudadanos. En efecto, según Hobbes, tanto las repúblicas como las monarquías absolutas restringen la libertad individual ya que ambas necesitan de leyes para gobernarse y las leyes cumplen, según él, el propósito específico de limitar la libertad natural del hombre. Es por eso que en un famoso pasaje del Leviathan Hobbes señala: "There is written on the Turrets of the city of Luca in great characters at this day, the word LIBERTAS; yet no man can thence inferre, that a particular man has more Libertie, or Immunitie from the service of the Commonwealth there, than in Constantinople. Whether a Commonwealth be Monarchicall, or Popular, the Freedome is still the same" ${ }^{54}$.

El concepto de libertad como no interferencia fue posteriormente rearticulado por Bentham ${ }^{55}$ para hacerlo compatible con la creciente legitimidad que ganaban los sistemas democráticos en la Europa del siglo XIX. Sin embargo, este concepto nunca perdió su indiferencia por las estructuras en las que se enmarcan las relaciones humanas ${ }^{56}$, ni su comprensión de la ley como un límite a la esfera de la libertad individual. Estas dos características de la libertad como no interferencia contrastan radicalmente con las características de la

53 Ibíd., 262.

54 Ibíd., 266.

55 De acuerdo a Skinner, el concepto hobbesiano de libertad quedó olvidado en el pensamiento político hasta su rescate en el siglo XIX, por obra de Bentham. Fue tal el olvido que Bentham se atribuyó a sí mismo su 'descubrimiento'. Ver SKInNER, Q. Liberty before Liberalism. Cambridge: Cambridge University Press, 1998, 83.

56 Por ello no es extraño que este concepto haya sido utilizado para defender el colonialismo y oponerse a la independencia de Estados Unidos. Ver, en particular, LIND, J. Three Letters to Dr. Price. London: T. Payne, 1776, 70. 
libertad republicana ${ }^{57}$. Para esta última las estructuras en las que se enmarcan las relaciones humanas son fundamentales para asegurar la libertad de los individuos: ellas no pueden permitir la dominación de unos sobre otros. Por otro lado, la ley, cuando es el producto de la capacidad de autogobierno colectivo y se orienta hacia el logro de fines que son aceptados de manera general como válidos, no es un límite a la libertad, sino una forma de hacerla posible $^{58}$. Lo es porque, si bien ella puede ser una forma de interferencia en la acción individual o colectiva, permite erradicar estructuras de dominación que, frente a su ausencia, tienen el potencial de surgir en los distintos ámbitos de la interacción social.

De las diferencias entre la libertad republicana y la libertad como no interferencia se siguen consecuencias relevantes para el argumento de este artículo. La primera es la afinidad entre las justificaciones democráticas de la libertad de expresión y el concepto republicano de libertad. Esta afinidad es la consecuencia de la relevancia que ambas categorías asignan a las estructuras en las que se enmarca la vida en común. Si desde una perspectiva republicana la libertad solo es posible cuando las estructuras sociales y políticas impiden la existencia de relaciones de dominación, la justificación democrática de la libertad de expresión persigue eliminar la dominación en los procesos de comunicación que se dan en la esfera pública. Y lo hace favoreciendo la participación en la discusión sobre asuntos de relevancia pública, facilitando los canales de comunicación entre la sociedad civil y el poder político, y sometiendo a este último al control permanente de la ciudadanía. Por otro lado, la afinidad entre la justificación democrática de la libertad de expresión y la libertad republicana pasa por el hecho de que ambas categorías ven en la ley un instrumento fundamental para la materialización de sus propósitos. Si bien la ley es una forma de interferencia en el ámbito de acción individual o colectiva, ella es compatible con la libertad republicana cuando -tal como ya se dijo- es el producto de la agencia colectiva y su propósito es alcanzar metas socialmente validadas. Asimismo, las justificaciones democráticas de la libertad de expresión defienden mecanismos legales que estimulen la participación de la pluralidad de voces existentes, refuercen la discusión sobre cuestiones de relevancia pública ${ }^{59}$ y prohíban discursos que tengan la cualidad de violentar o degradar a sus destinatarios ${ }^{60}$.

La segunda conclusión que se sigue de la distinción entre los conceptos de libertad es la afinidad que existe entre el concepto de libertad como no

57 Así lo confirma el propio Berlin en su famosa defensa a la libertad negativa. Ver BERLIN. Two Concepts of Liberty, cit., 176.

58 Petтाт. Republicanism: A Theory of Freedom and Government, cit., 36-37.

59 Véase, en particular, Sunstein. Democracy and the Problem of Free Speech, cit.

60 En este sentido, Fiss, O. The Irony of Free Speech. Cambridge, Mass.: Harvard University Press, 1996. 
interferencia y la justificación de la libertad de expresión basada en la autonomía ${ }^{61}$. Los principales exponentes de esta justificación afirman que el desarrollo de la agencia moral es indisociable de la ausencia de interferencia estatal en el ámbito de la expresión. De acuerdo a Dworkin, una característica fundamental de una organización política justa es que ella trata a sus miembros adultos como agentes morales responsables. Esto implica reconocer que estos son capaces de formar por sí mismos sus concepciones acerca de lo que es correcto, justo o bueno, y que la intervención estatal, ya sea para evitar las consecuencias dañosas que puedan seguirse de ciertos discursos (como los discursos del odio) o la formación de convicciones ofensivas, violaría el respeto que los agentes morales se merecen ${ }^{62}$. Aquí es importante aclarar que si bien para la tradición liberal la acción estatal es siempre una forma de afectación de la libertad individual ${ }^{63}$, en especial en el ámbito de la libertad de expresión, ciertas interferencias son toleradas cuando sean necesarias para resguardar otros valores (como la seguridad o la privacidad) ${ }^{64}$. Sin embargo, por las razones ya esgrimidas, el umbral de tolerancia liberal a la acción del Estado es bastante bajo.

Estas distinciones son claves para definir la relación entre libertad y pluralismo informativo y los mecanismos para asegurar su tutela, tarea que se aborda en la siguiente y última sección del artículo. Tal como se pasa a ver, ambos conceptos de libertad dan respuestas distintas al modo en que los canales de televisión deben organizarse para garantizar el respeto a la diversidad de enfoques y perspectivas existentes en una sociedad.

\section{PLURALISMO Y LIBERTAD}

El pluralismo externo y el pluralismo interno son los dos grandes modelos bajo los cuales se ha estructurado el pluralismo informativo en los sistemas de comunicación occidentales ${ }^{65}$. El pluralismo externo se manifiesta en la estructura de los medios de comunicación, y lo mediante la existencia de

61 Para un análisis en detalle sobre este punto, véase ChARnEY, J. The Illusion of the Free Press. Oxford: Hart Publishing, 2018, 94-96.

62 En este sentido, véase Dworkin. The coming Battles over Free Speech, cit.; SCANLON, T. Freedom of Expression and Categories of Expression. En University of Pittsburgh Law Review. Vol. 40, 1979, 519.

63 Este punto es enfáticamente expresado por Berlin cuando dice que "law is always a fetter, even if it protects you from being bound in chains that are heavier than those of the law". BerLin, I. Four Essays on Liberty. Oxford: Oxford University Press, 1969, 3.

64 El propio J. S. Mill, señala que "[a]n opinion that corn dealers are starvers of the poor, or that private property is robbery, ought to be unmolested when simply circulated through the press, but may justly incur punishment when delivered orally to an excited mob assembled before the house of a corn dealer". MILL. On Liberty, cit., 67-68.

65 Hallin, D. y Mancini, P. Comparing Media Systems: Three Models of Media and Politics. Cambridge: Cambridge University Press, 2004, 14. 
una diversidad de organizaciones, cada una de las cuales controla un medio de comunicación en el que refleja sus puntos de vista y opiniones particulares. La suma de estos medios representa los puntos de vista y opiniones de los distintos grupos y tendencias existentes en una sociedad. El pluralismo externo puede obtenerse mediante una estructura de medios en la que conviven diversas formas de propiedad, organización jurídica y económica, como por ejemplo, aquellos que combinan televisión pública y televisión privada. Puede obtenerse, además, cuando la propiedad de los medios se encuentra adecuadamente distribuida entre distintos grupos y organizaciones que conforman la totalidad (o buena parte) del tejido social ${ }^{66}$. Las normas contenidas en la ley de televisión digital que permiten otorgar a Televisión Nacional una segunda concesión para transmitir señales (propias o de otros concesionarios) de carácter regional y la que establece la obligación de los permisionarios de servicios limitados de difundir canales regionales, locales o comunitarios son normas que apuntan a fortalecer el pluralismo externo del sistema televisivo.

El pluralismo interno, a diferencia del anterior, es aquel en el que el pluralismo se manifiesta en los contenidos de cada medio de comunicación en particular. En este sistema todos los medios deben transmitir las opiniones y visiones que representen a los distintos grupos y tendencias existentes. Este concepto ha sido utilizado de dos maneras por la literatura. La primera se relaciona con el gobierno interno de los medios de comunicación. Se da especialmente en la televisión, cuando sus directorios u órganos de gobierno y administración están compuestos por miembros que representan todo el espectro político ${ }^{67}$. La segunda corresponde a aquellos sistemas en los cuales los medios de comunicación evitan conexiones institucionales con grupos políticos y buscan transmitir contenidos neutros o balanceados ${ }^{68}$. Característica de este segundo tipo de pluralismo interno es la norma contenida en la ley de televisión digital chilena que obliga a los canales de televisión a respetar el pluralismo en sus programas de noticias. La norma señala que el pluralismo es "el respeto a la diversidad social, cultural, étnica, política, religiosa, de género, de orientación sexual e identidad de género siendo deber de los concesionarios y permisionarios de servicios de televisión, regulados por esta ley, la observancia de estos principios". Para tutelar el respeto a la diversidad, el Consejo Nacional de Televisión podrá aplicar sanciones cuando la norma haya sido infringida, pudiendo estas, de acuerdo a su gravedad, consistir en amonestaciones, multas, suspensión de transmisiones y caducidad de la

66 Hitchens, L. Broadcasting Pluralism and Diversity: A Comparative Study of Policy and Regulation. Oxford: Hart, 2006, 9.

67 Ibíd., 30.

68 Supra, nota 66, 29. 
concesión, en casos calificados. Estas sanciones pueden ser apeladas ante la Corte de Apelaciones y, en el caso de caducidad, ante la Corte Suprema.

El modo bajo el cual el sistema de televisión se organiza para garantizar el pluralismo informativo (pluralismo externo/pluralismo interno) depende de un conjunto de condiciones políticas, históricas, jurídicas y culturales. Y si bien existe amplio consenso sobre la importancia de garantizar el pluralismo informativo, la discrepancia radica en cómo debe hacerse. En lo que sigue se argumenta que, cualquiera que sea el modelo que se siga, incluido un modelo que combine mecanismos de pluralismo externo y de pluralismo interno, la efectiva protección de este principio depende del concepto de libertad bajo el cual el sistema se sostenga. Para una exposición más nítida se comienza por el análisis del pluralismo externo, para finalizar con el pluralismo interno.

\subsection{Pluralismo externo}

Articulada bajo un concepto de libertad como no interferencia, la configuración sistémica del sistema de televisión debe ser el producto del libre juego de los agentes del mercado, un juego que debiese quedar, hasta donde sea posible, libre de la interferencia estatal. Ese es el modo de garantizar la libertad empresarial de los canales, su autonomía como cuerpos intermedios de la sociedad, el respeto al principio de la subsidiariedad, y la libertad de expresión. Esto significa que, manteniendo el Estado el control sobre el sistema de concesiones de las señales de radiodifusión televisiva, su finalidad debiera ser incentivar la entrada de nuevos operadores, bajo condiciones competitivas que permitan un uso eficiente de las posibilidades de negocios que la digitalización de la televisión abre ${ }^{69}$. Los canales de televisión, desde esta perspectiva, no debiesen estar sujetos a modos de regulación distintos a los de cualquier otro mercado. En la medida en que así sea, la libre competencia en el mercado televisivo generará una multiplicidad de operadores que desarrollarán, a su vez, contenidos diversos ${ }^{70}$. Por estas razones, desde esta perspectiva, se ha preferido el pluralismo externo por sobre el pluralismo interno de los medios de comunicación.

69 Es la versión que defiende Sierra. Hacia la televisión digital en Chile: historia y transición, cit., 144.

70 Esto aparece expresado en el voto minoritario del Tribunal Constitucional con ocasión del requerimiento de inconstitucionalidad de la ley de TVDT cuando sostiene que "es justamente la presencia de múltiples operadores y la consiguiente variedad en el contenido de las transmisiones, lo que asegura un auténtico pluralismo en el sector, el cual redunda en el efectivo desarrollo y flujo de las más dispares percepciones, pensamientos e ideas que circulan dentro de la colectividad". STC 2541-13 de 18 de noviembre de 2013, párr. 10. La relación de causalidad entre pluralismo estructural y diversidad de contenidos es también uno de los presupuestos de la ley de prensa que en su artículo 3 . $^{\circ}$ establece que el "pluralismo en el sistema informativo favorecerá la expresión de la diversidad social, cultural, política y regional del país. Con este propósito se asegurará la libertad de fundar, editar, establecer, operar y mantener medios de comunicación social". 
Dos grandes problemas se siguen, en materia de pluralismo, cuando la estructura de la televisión queda plenamente entregada a las reglas del mercado. El primero de ellos fue detectado con gran claridad por Doyle ${ }^{71}$. Según este, las características particulares del mercado de la televisión plantean serias dificultades a la teoría económica, ya que la diversidad en la propiedad de concesiones televisivas no produce, necesariamente, diversidad de contenidos y visiones ${ }^{72}$. La explicación se encuentra en que los canales de televisión abierta no obtienen ganancias directamente de las audiencias sino que lo hacen a través de los avisadores ${ }^{73}$. Por este motivo deben generar contenidos que sean atractivos para las grandes audiencias, contenidos que necesariamente excluyen los gustos e intereses de las minorías. Esto produce el fenómeno de la duplicación competitiva, y explica por qué las parrillas programáticas de los canales de televisión son muy similares entre sín ${ }^{74}$. Las conclusiones de Doyle coinciden con una extensa literatura ${ }^{75}$. La dependencia respecto de los grandes avisadores tiene un impacto en la selección y producción de contenidos informativos que acentúa el sensacionalismo (que busca impactar antes que informar), el abuso de la crónica roja (en desmedro del periodismo investigativo) y la hipérbole, entre muchos otros fenóme$\operatorname{nos}^{76}$. En consecuencia, cuando la estructura de la televisión no lo permite, algún tipo de regulación interna se requiere para prevenir el fenómeno de la duplicación competitiva e incrementar el pluralismo y la diversidad en los

71 De acuerdo a Doyle, estudios en el mercado de televisión en Estados Unidos han demostrado que los mercados de televisión no regulados producen más contenidos con externalidades negativas que los mercados regulados. Ejemplos de los anteriores son el exceso de prensa roja, la farandulización de las noticias y la violencia excesiva. Ver Doyle, G. Understanding Media Economics. London: Sage Publications, 2002, 10-11.

72 Así lo demuestra además Hargreaves, H. Television in a Digital Age: What Role for Public Service Broadcasting? En Economic Policy. Vol. 20, n. ${ }^{\circ}$ 41, 2005.

73 Supra, nota $73,10-11$.

74 Ibíd., 74.

75 Ver Herman, E. y Chomsky, N. Manufacturing Consent: The Political Economy of the Mass Media. London: Vintage, 1995; Bagdikian, B. The New Media Monopoly. 7. a ed. Boston, Mass, Beacon, 2004; Curran, J. y Seaton, J. Power without Responsibility: Press, Broadcasting and the Internet in Britain. Oxford: Routledge, 2010; MonCKEBERG, M. O. Los magnates de la prensa: concentración en los medios de comunicación. Santiago: Debate, 2008; Couso, J. El mercado como obstáculo a la libertad de expresión: la concentración de la prensa escrita en Chile en la era democrática. En Plataforma Democrática, 2011. Disponible en: http://www. plataformademocratica.org/Arquivos/Plataforma_Democratica_Working_Paper_23_2011_Espanhol.pdf (Consultado el 20 de octubre de 2017).

76 Este fenómeno no se modifica con la introducción de la televisión digital, tal como se ha demostrado con el proceso de digitalización en Europa. Debido a los costos asociados a la producción de contenidos y a la captación de nuevas audiencias, muchos canales han decidido importar programas masivos y de bajo costo, especialmente de Estados Unidos, o reciclar programas antiguos y hacerlos disponibles en diversos formatos. Ver, al respecto, IosifiDis, $\mathrm{P}$. Public Television in the Digital Era: Technological Challenges and New Strategies for Europe. New York: Palgrave Macmillan, 2007, 36. 
contenidos y visiones de los canales de televisión ${ }^{77}$. Esto es, sin embargo, incompatible con un concepto de libertad como no interferencia, toda vez que dicha regulación requiere de interferencia estatal en la esfera de acción de los canales de televisión.

El segundo problema del concepto de libertad como no interferencia en materia de pluralismo externo es el efecto que su aplicación produce en la concentración de la propiedad. Para evitar los altos costos de programación asociados a la producción de contenidos televisivos, así como el personal altamente calificado que ha de utilizarse, los canales de televisión han diseñado e implementado estrategias comerciales de fusión o integración vertical, horizontal y diagonal que los han ayudado a aprovechar las economías de escala existentes en el mercado de la televisión ${ }^{78}$. Estas estrategias se benefician de mercados desregulados o con bajos niveles de regulación, y afectan no solo a la televisión sino a los medios de comunicación en general ${ }^{79}$. Uno de los principales problemas de la concentración en la propiedad es que produce estructuras de dominación que afectan el proceso de formación de la opinión pública. En efecto, cuando son solo unos pocos agentes los que participan de la generación de información periodística, tanto a nivel local ${ }^{80}$ como global, los riesgos de que esos agentes puedan utilizar ese poder en su propio beneficio equivalen a una forma de dominación que afecta invariablemente la libertad de $\operatorname{todos}^{81}$. Si lo anterior es un atentado intolerable a la libertad republicana, no lo es a la libertad como no interferencia, ya que de la concentración en la propiedad no se siguen necesariamente actos específicos e identificables que constriñan materialmente el ejercicio de los poderes del individuo.

Desde la perspectiva republicana, la dispersión en la propiedad es un valor en sí mismo y no uno que pueda predicarse en virtud de sus resulta$\operatorname{dos}^{82}$. De este modo, la diversidad en la propiedad no pierde su valor si ella

77 Es por este motivo que la gran mayoría de los países han introducido diversas medidas regulatorias en sus sistemas de televisión. Ver McKinseY \& Company. Review of Public Service Broadcasting around the World.2004. Disponible en: https://www.ofcom.org.uk/_data/assets/ pdf_file/0018/34236/wp3mck.pdf (Consultado el 20 de octubre de 2017).

78 Supra, nota $73,60-61$.

79 Para los efectos de la concentración de la propiedad en los medios de comunicación, ver McChesney, R. Digital Disconnect. New York: The New Press, 2013,73-76. Ver, además, el ranking del Institute of Media and Communications Policy, en: http://www.mediadb.eu/en.html

80 Sobre los efectos de la concentración de la propiedad de los medios de comunicación en Chile, ver Ruiz-Tagle, P. Propiedad de los medios y principios de intervención del Estado para asegurar la libertad de expresión en Chile. En Revista de Derecho Universidad Católica del Norte. Año 18, n. ${ }^{\circ} 2,2011,352$.

81 Ver Supra n. 81,73-76.

82 De acuerdo a Baker, la versión consecuencialista del pluralismo es propia de las ciencias económicas: se enfoca en el bienestar del consumidor y olvida la importancia que el pluralismo estructural tiene en las libertades políticas y en el sistema democrático en su conjunto. BAKER, E. Media Concentration and Democracy: Why Ownership Matters. New York: Cambridge University Press, 2007, 15. 
no produce diversidad de contenidos. Por otro lado, si de este sistema se sigue pluralidad de contenidos y puntos de vista, el resultado será valorado por el sistema mismo en el que se produjo. La importancia de la dispersión en la propiedad, desde la perspectiva republicana, es que ella constituye un presupuesto básico de la libertad ya que reduce las relaciones de dominación existentes ${ }^{83}$. En primer lugar, permite que la diversidad de visiones existentes en la sociedad puedan participar en la construcción de la opinión pública. En segundo lugar, elimina la posibilidad de que un número limitado de operadores puedan utilizar su poder para interferir arbitrariamente en la discusión en la esfera pública. Esto último es fundamental para quienes creen, como lo hacen los republicanos, que la mera conciencia de vivir en un sistema que tolera la posibilidad de interferencia arbitraria constituye un serio atentado a la libertad. De lo anterior se sigue una segunda diferencia que caracteriza la relación entre libertad y pluralismo cuando la libertad es entendida desde una perspectiva republicana. Si el pluralismo estructural es esencial para garantizar la libertad y el primero no se logra a través de las reglas del laissez faire (tal como se vio en la sección anterior), entonces es necesaria la interferencia del Estado. La interferencia estatal en la organización de la estructura de los medios de comunicación afecta la libertad cuando esta se define como ausencia de interferencia, mas no cuando esta es definida desde una perspectiva republicana. Así, las normas contenidas en la ley de televisión digital que apuntan a regular la estructura del sistema televisivo y que obligan a los permisionarios a transmitir canales regionales, y que conceden a Televisión Nacional una segunda concesión para transmitir señales locales o regionales, si bien pueden entenderse como restricciones a la libertad como no interferencia, son compatibles con un concepto republicano de libertad.

\subsection{Pluralismo interno}

Las reglas de pluralismo interno también pueden ser compatibles con la libertad republicana cuando sirvan para reducir o erradicar relaciones de dominación, como podría suceder con aquellas que refuerzan el respeto a la diversidad y el derecho a la información. Así, una regla como la establecida en la ley chilena, que obliga a los canales de televisión a respetar el principio del pluralismo en sus programas de noticias y de opinión política, no es ipso facto contraria a la libertad. Ahora bien, dado que la regulación de contenidos es especialmente invasiva y requiere de controles de órganos administrativos para asegurar su respeto, debe ser cuidadosamente diseñada. De lo contrario,

83 Esto por cuanto la libertad republicana (a diferencia de la libertad como no interferencia) es incompatible con la conciencia de vivir bajo un sistema que admita la mera posibilidad de interferir arbitrariamente en nuestras opciones significativas. Ver SKInNER, Q. La libertad de las repúblicas: ¿un tercer concepto de libertad? En Isegoría. Vol. 33, 2005, 40. 
dicha regulación podría transformarse en un instrumento de dominación que podría afectar indebidamente el libre intercambio de ideas en la esfera pública. Por las razones que a continuación se detallan, este no es el caso de la regla de pluralismo interno contenida en la ley de televisión digital chilena.

La estructura y el consumo de televisión han cambiado enormemente en los últimos años. Junto con la introducción de la televisión digital se han incorporado formatos de отт (como Netflix) y plataformas como Youtube o Facebook que han incrementado exponencialmente el universo de contenidos disponibles. Tal como se analiza en la primera sección de este artículo, esta fue una de las razones que se utilizó para alegar la inconstitucionalidad de la regla de pluralismo interno contenida en la ley de televisión digital. El argumento es que en una atmósfera televisiva en la que ya no existe escasez espectral y en la que hay espacio para múltiples operadores no se justificarían reglas tendientes a asegurar el pluralismo interno. Si bien el supuesto empírico sobre el que se sostiene este argumento es válido, es necesario tener presente que la televisión sigue siendo el principal instrumento por medio del cual la ciudadanía se informa del acontecer político en Chile ${ }^{84}$. En ese sentido, el resguardo efectivo del pluralismo informativo queda entregado, en una medida importante, al desempeño que los canales de televisión exhiben en sus noticiarios y programas de debate político. Ahora bien, la regla de pluralismo interno contenida en la ley de televisión digital no impone a los canales la obligación de asegurar la expresión de las distintas visiones existentes en la sociedad. Tampoco les exige que estas reciban un trato equitativo. La regla solo establece una obligación negativa: prohíbe que los canales de televisión (en sus programas de noticias y debate político, y solo en ellos) falten al debido respeto al conjunto de visiones y estilos de vida existentes en la sociedad ${ }^{85}$. Así entendida, la regla del pluralismo interno establece una obligación de no ofender. En este sentido, el argumento que sostiene que frente al incremento de operadores televisivos las reglas de pluralismo interno pierden justificación (como la contenida en la ley de televisión digital) no es válido. En efecto, mientras más operadores televisivos existan, mayores serán los contenidos transmitidos por los canales de televisión, y con ello mayores las posibilidades (y por tanto el riesgo) de que se infrinja el respeto

84 En Chile más del 80\% de la población se informa del acontecer nacional e internacional a través de los canales de televisión abierta. Véase CNTV. Novena Encuesta Nacional de Televisión, 2017,51. Disponible en: https:/www.cntv.cl/cntv/site/artic/20171012/asocfile/20171012121426/ ix_encuesta_nacional_de_television.pdf

$85 \mathrm{Si}$ bien el proyecto de ley original pretendía establecer una obligación positiva de respeto al pluralismo en cabeza de los canales de televisión (la norma original establecía que los canales debían "promover en los contenidos entregados la observancia de estos principios"), mediante un veto presidencial tal obligación fue suprimida, quedando la redacción como se lee en el texto en vigor. 
a la diversidad. En tal escenario, la regla de pluralismo interno contenida en la ley de televisión digital chilena se justifica plenamente.

Por otra lado, la 'obligación de no ofender' contenida en la ley de televisión digital chilena es un modo de aplacar estructuras de dominación. Como lo señala Fiss, la expresión de discursos ofensivos daña el proceso de autodeterminación colectivo. Esto se debe a que en un sistema democrático, las personas diseñan sus planes de vida de acuerdo a las distintas concepciones y visiones sociales existentes, muchas de las cuales se manifiestan en la discusión que se da en la esfera pública ${ }^{86}$. Según Fiss, los discursos ofensivos afectan este proceso ya que producen un efecto silenciador en sus víctimas. Al disminuir la autoestima de sus destinatarios, estos discursos debilitan sus capacidades de participar plenamente en la vida social, incluida su participación en la discusión en la esfera pública ${ }^{87}$. Los discursos ofensivos constituyen formas de dominación que debilitan la esfera pública y el proceso de autodeterminación colectivo. Por esa razón, la libertad se refuerza en la medida en que tales discursos sean restringidos, en especial en aquellos programas que contribuyen a la formación de la opinión pública, como son los noticiarios y los programas de debate político.

Por último, la regla que establece la obligación de los canales de televisión de respetar la diversidad no crea nuevas estructuras de dominación. En primer lugar, la regla se limita a establecer una obligación negativa a los canales de televisión: la de no ofender la diversidad de formas de vida y visiones existentes en la sociedad. Por otro lado, la obligación de respeto a la diversidad no se extiende a toda la programación de los canales de televisión, sino solo a la de los programas de noticias y de opinión política, puesto que ellos son los de mayor influencia en la formación de la opinión pública. Finalmente, las sanciones que puede aplicar el órgano administrativo a los canales de televisión son siempre apelables. Dicha apelación se realiza ante la Corte de Apelaciones y, en caso de caducidad (en casos calificados), ante la Corte Suprema. En definitiva, la ley establece un marco de mínimo respeto en la discusión que se da en programas relevantes para el proceso de formación de la opinión pública, y establece mecanismos de protección para los legítimos derechos de los canales frente a potenciales abusos del órgano administrativo.

Normas de pluralismo interno que signifiquen mayores niveles de interferencia en las decisiones de los canales de televisión podrían, eventualmente, ser compatibles con la libertad republicana. Es evidente que para verificar dicha compatibilidad habría que analizar la norma y las circunstancias concretas de su aplicación. Sin perjuicio de lo anterior, el concepto republicano de libertad es más tolerante que el liberal a reglas legales de pluralismo interno orientadas a ampliar la gama de contenidos informativos y a crear

86 Fiss. The Irony of Free Speech, cit., 3.

87 Ibíd., 16. 
estándares de comunicación respetuosos de la diversidad. Esto es así puesto que, si bien estas reglas interfieren en el ámbito de decisión de los canales (y por tanto lesionan la libertad desde el concepto liberal), ellas tienden a disminuir el riesgo de dominación (y con ello refuerzan la libertad republicana). Lo hacen, en primer lugar, porque una ciudadanía informada es un presupuesto básico para la participación de la ciudadanía en los asuntos de relevancia colectiva. Por otro lado, la diversidad de información y puntos de vista facilita el control sobre las acciones de la autoridad y sobre los poderes económicos. Asimismo, cuando la libertad de expresión se enmarca en un diálogo que obliga a respetar la pluralidad de voces existentes en una comunidad, abriendo espacios para aquellas que se encuentran marginadas $\mathrm{y}$ reduciendo el de aquellas que se niegan a respetar el encuentro respetuoso en la diversidad, entonces el riesgo de que la visión de unos se imponga por sobre la de otros disminuye ${ }^{88}$.

\section{CONCLUSIONES}

El concepto de libertad sobre el que se construyen las defensas de la libertad de expresión presentadas en este artículo tiene consecuencias en el modo de regulación del pluralismo informativo en la televisión. Mientras que la libertad negativa asociada a una defensa de la autonomía de los canales de televisión como cuerpos intermedios rechaza la interferencia estatal en el diseño de la estructura televisiva y en la producción de contenidos, la libertad republicana asociada a una defensa democrática de la libertad de expresión acepta la regulación estatal del pluralismo en la televisión en la medida en que ella potencie las libertades políticas de los ciudadanos. La regulación es necesaria desde una perspectiva republicana por cuanto su ausencia produce formas de dominación, tanto en la estructura del sistema como en los contenidos. Desmantelar esas estructuras de dominación se transforma entonces en una tarea primordial para garantizar las libertades políticas de los ciudadanos en un sistema democrático.

\section{REFERENCIAS}

Arendt, H. Freedom and Politics. En Miller, D., The Liberty Reader. Edinburgh: Edinburgh University Press, 2006, 58-79.

Atria, F. Autonomía universitaria y universidad pública. 2016. Disponible en: http://www. elmostrador.cl/noticias/pais/2016/11/01/autonomia-universitaria-y-universidadpublica/ (Consultado el 20 de octubre de 2017).

Bagdikian, B. The New Media Monopoly. 7. a ed. Boston, Mass.: Beacon, 2004. 
BAKer, E. Human Liberty and Freedom of Speech. New York: Oxford University Press, 1993.

BAKer, E. Media Concentration and Democracy: Why Ownership Matters. New York: Cambridge University Press, 2007.

Barendt, E. Freedom of Speech. 2. ed. Oxford: Oxford University Press, 2007.

BвC. Public and Private Broadcasters across the World. 2013. Disponible en: https:// downloads.bbc.co.uk/aboutthebbc/insidethebbc/howwework/reports/pdf/bbc_report_public_and_private_broadcasting_across_the_world.pdf (Consultado el 20 de octubre de 2017).

Bentham, J. On the Liberty of the Press. En Bowring, J., The Works of Jeremy Bentham. Edinburgh: William Tait, 1843.

Berlin, I. Two Concepts of Liberty. En Hardy, H., Liberty. Oxford: Oxford University Press, 2002, 166-217.

Blasi, V. The Checking Value in First Amendment Theory. En American Bar Foundation Research Journal. Año 2, n. ${ }^{\circ}$ 3, 1977, 521-649.

BRIson, S. The Autonomy Defense of Free Speech. En Ethics. Vol. 108, n. ${ }^{\circ}$ 2, 1998, 312-339.

Bronfman, A., Martínez, J. I. y Núñez, M. Constitución Política comentada. Santiago: Legal Publishing, 2012.

Brunner, J. J. y Catalán, C. Televisión, libertad, mercado y moral. Santiago: Los Andes, 1995.

Castells, M. The Rise of the Network Society. Vol. 1. 2. ed. Sussex: Wiley-Blackwell, 2010.

CeA, J. L. Derecho constitucional chileno. T. 2. Santiago: Pontificia Universidad Católica de Chile, 2012.

Charney, J. The Illusion of the Free Press. London: Hart, 2018.

Christman, J. Autonomy in Moral and Political Philosophy. En Stanford Encyclopedia of Philosophy. 2011. Disponible en: https://plato.stanford.edu/archives/spr2011/entries/ autonomy-moral/ (Consultado el 20 de octubre de 2017).

Couso, J. El mercado como obstáculo a la libertad de expresión: la concentración de la prensa escrita en Chile en la era democrática. En Plataforma Democrática. 2011. Disponible en: http://www.plataformademocratica.org/Arquivos/Plataforma_Democratica_Working_Paper_23_2011_Espanhol.pdf (Consultado el 20 de octubre de 2017).

Curran, J. y Seaton, J. Power without Responsibility: Press, Broadcasting and the Internet in Britain. Oxford: Routledge, 2010.

Doyle, G. Understanding Media Economics. London: Sage Publications, 2002.

Dworkin, G. Autonomy and Behavior Control. En Hasting Center Report. Año 6 n. ${ }^{\circ}$, 1976, 23-28. 
Dworkin, R. The coming Battles over Free Speech. En The New York Review of Books. 11 de junio de 1992.

Elster, J. Ulyses Unbound. Cambridge: Cambridge University Press, 2000.

Fenwick, H. y Phillipson, G. Media Freedom under the Human Rights Act. Oxford: Oxford University Press, 2006.

FIss, O. The Irony of Free Speech. Cambridge, Mass.: Harvard University Press, 1996.

Fiss, O. Why the State? En Lichtenberg, J., Democracy and the Mass Media. Cambridge: Cambridge University Press, 2008, 136-154.

Hallin, D. y Mancini, P. Comparing Media Systems: Three Models of Media and Politics. Cambridge: Cambridge University Press, 2004.

Hargreaves, H. Television in a Digital Age: What Role for Public Service Broadcasting? En Economic Policy. Vol. 20, n. ${ }^{\circ}$ 41, 2005, 112-157.

Herman, E. y Chomsky, N. Manufacturing Consent: The Political Economy of the Mass Media. London: Vintage, 1995.

Hitchens, L. Broadcasting Pluralism and Diversity: A Comparative Study of Policy and Regulation. Oxford: Hart Publishing, 2006.

Hobbes, T. Leviathan. London: Penguin Classics, 1985.

Iosifidis, P. Public Television in the Digital Era: Technological Challenges and New Strategies for Europe. New York: Palgrave Macmillan, 2007.

Lind, J. Three Letters to Dr. Price. London: T. Payne, 1776.

Loughlin, M. Foundations of Public Law. Oxford: Oxford University Press, 2010.

McChesney, R. The Political Economy of International Communications. En Mchesney, R., The Political Economy of the Media. New York: Monthly Review Press, 2008, 305-338.

McChesney, R. Digital Disconnect. New York: The New Press, 2013.

McKinsey \& Company. Review of Public Service Broadcasting around the World. 2004. Disponible en: https://www.ofcom.org.uk/__data/assets/pdf_file/0018/34236/wp3mck. pdf (Consultado el 20 de octubre de 2017).

Meiklejohn, A. Free Speech and its Relation to Self-Government. En Meiklejohn, A., Political Freedom: The Constitutional Power of the People. New York: Oxford University Press, 1965.

Mill, J. S. On Liberty. New York: Cosimo Classics, 2005.

Milton, J. Areopagitica. Champaign, Il.: Standard Publications, 2008.

Mönckeberg, M. O. Los magnates de la prensa: concentración en los medios de comunicación. Santiago: Debate, 2008. 
O’NeILL, O. News of this World. 2011. Disponible en: https://www.ft.com/content/25c0d3160ec6-11e1-9dbb-00144feabdc0 (Consultado el 20 de octubre de 2017).

Pettit, P. Republicanism: A Theory of Freedom and Government. Oxford: Oxford University Press, 1997.

Post, R. Participatory Democracy and Free Speech. En Virginia Law Review. Vol. 97, n. ${ }^{\circ} 3,2011,477-489$.

RAz, J. Free Expression and Personal Identification. En Oxford Journal of Legal Studies. Vol. 11 n. ${ }^{\circ}$ 3, 1991, 303-324.

Ruiz-Tagle, P. Propiedad de los medios y principios de intervención del Estado para asegurar la libertad de expresión en Chile. En Revista de Derecho Universidad Católica del Norte. Año 18, n. $^{\circ} 2,2011,347-359$.

Scanlon, T. Freedom of Expression and Categories of Expression. En University of Pittsburgh Law Review. Vol. 40, 1979, 519.

Sierra, L. Hacia la televisión digital en Chile: historia y transición. En Estudios Públicos. Vol. 103, 2006, 111-154.

SkINNER, Q. Liberty before Liberalism. Cambridge: Cambridge University Press, 1998.

SKInNer, Q. La libertad de las repúblicas: ¿un tercer concepto de libertad? En Isegoría $33,2005,19-49$.

Skinner, Q. Hobbes and Republican Liberty. Cambridge: Cambridge University Press, 2008.

Sunstein, C. Democracy and the Problem of Free Speech. New York: The Free Press, 1995.

Waldron, J. Moral Autonomy and Personal Autonomy. En Christman, J. P. y Anderson, J., Autonomy and the Challenges to Liberalism. Cambridge: Cambridge University Press, 2005, 307-329. 